\title{
Lack of facilities rather than sociocultural factors as the primary barrier to physical activity among female Saudi university students
}

This article was published in the following Dove Press journal:

International Journal of Women's Health

9 March 2015

Number of times this article has been viewed

\author{
Anastasia Samara' \\ Anne Nistrup' \\ Tamader Y AL-Rammah² \\ Arja R Aro' \\ 'Unit for Health Promotion \\ and Research, University of Southern \\ Denmark, Esbjerg, Denmark; ${ }^{2}$ Faculty \\ of Rehabilitation and Health Sciences, \\ Princess Nora Bint Abdul Rahman \\ University, Riyadh, Kingdom of Saudi \\ Arabia
}

Purpose: The Kingdom of Saudi Arabia is experiencing a dramatic increase in physical inactivity, with women having higher levels of inactivity than men among all age groups. It is assumed that factors such as dress codes, restrictions on going outdoors, and conservative norms are the main reasons for women's low physical activity. Our aim was to explore the different parameters related to physical activity, including self-efficacy, as well as the perceived barriers to and benefits of physical activity in young Saudi females.

Patients and methods: Ninety-four first-year female Saudi university students in Riyadh, Kingdom of Saudi Arabia, participated in the present study in 2014. The students were from eight bachelor's programs in health and well-being, and each completed a questionnaire with questions divided into five parts as follows: 1) socioeconomic status, 2) physical activity, 3) self-efficacy 4) social factors, and 5) barriers and facilitators related to physical activity.

Results: The students exercised at home and alone, and there was low self-efficacy for physical activity (mean score $=42 \pm 14$ ). Among social factors, attending university was the only factor that hindered physical activity (32\%). Physical activity was positively perceived overall (mean score $=131 \pm 10$ ). Students showed awareness of the benefits of physical activity for health and wellbeing. The most important barrier was the lack of designated areas available for physical activity. Students disagreed that family or the Islamic community were barriers to physical activity.

Conclusion: The lack of facilities and lack of encouragement from the university, but not a lack of knowledge (a high level of knowledge is to be expected given their health and wellbeing studies backgrounds) and/or restrictions from families and society, seem to hinder female students' physical activity, at least young Saudi students.

Keywords: physical activity, Kingdom of Saudi Arabia, females, barriers and facilitators, self-efficacy

\section{Introduction}

Rapidly developing countries such as the Kingdom of Saudi Arabia (KSA) have experienced a dramatic decrease in physical activity mostly because of economic prosperity and industrialization, and especially in urban areas such as Riyadh, KSA. Data from the World Health Organisation (WHO) report on the KSA in 2005 show overall low percentages of high (16\%) and moderate (16\%) physical activity, and high percentages of low (68\%) activity among men and women 15-65 years old. ${ }^{1}$ Others have also described high prevalence of physical inactivity among Saudis. ${ }^{2,3}$ Data from a comparative study on 20 countries showed that the KSA was among the countries that reported the highest amounts of time spent sitting. ${ }^{4}$

Studies have shown that women in the KSA are more inactive than men in all age groups, ${ }^{1,3,5}$ and this is also the case for other countries in the Gulf Cooperation Council. ${ }^{6}$
Correspondence: Anastasia Samara Unit for Health Promotion Research, University of Southern Denmark, Niels Bohrs Vej 9, 6700 Esbjerg, Denmark Tel +4565504256

Email asamara@health.sdu.dk (c) (i) (5) 2015 Samara et al. This work is published by Dove Medical Press Limited, and licensed under Creative Commons Attribution - Non Commercial (unported, v3.0) License. The full terms of the License are available at http://creativecommons.org/licenses/lby-nc/3.0/. Non-commercial uses of the work are permitted without any further permission from Dove Medical Press Limited, provided the work is properly attributed. Permissions beyond the scope of the License are administered by Dove Medical Press Limited. Information on how to request permission may be found at: http://www.dovepress.com/permissions.php 
A considerable number of studies have been performed on Saudi adolescents ${ }^{7-11}$ and young adults, including university students, ${ }^{12,13}$ and they show similar results in relation to sex. In addition, in cross-cultural studies, Saudi female youth appear to be more sedentary and to have lower physical activity levels compared to female British youth. ${ }^{14,15}$

The reasons for the sedentary behaviors and low physical activity levels among Saudi women compared with both Saudi men and women from other countries are poorly explored. Saudi Arabian society, especially in urban areas, shows a combination of modernity mixed with traditional roles, values, and conservative social norms, especially for women. This is a unique socioeconomic, environmental, and cultural context that needs to be further understood. There are certain sociocultural factors that appear to be barriers to women's physical activity, such as low education levels, ${ }^{16}$ wearing an abaya outside, depending on a driver, limited freedom of movement outside of the house, and employing domestic helpers. However, high socioeconomic status might, as in Western countries, contribute to access to health clubs (especially in the large cities where they are available), having physical activity equipment at home, and being more liberal - both the women themselves and their families. In addition, hot weather is an important barrier for exercising outdoors both for men and women. Men also experience significant barriers such as low education, employing domestic helpers, and frequent use of automobiles, but they have more freedom of movement outside of the home.

Very few studies have addressed these issues, ${ }^{13,17,18}$ and those that have, did so from a limited perspective. To our knowledge, no study has extensively explored the sociocultural factors that contribute to low physical activity among women in the KSA. This would aid the understanding of which factors are the most important and, therefore, allow the implementation of effective health promotion strategies in the future, particularly for young Saudi adults.

University students are an interesting population to study and to target for change, for multiple reasons: 1) they are relatively easy to access; 2) the university is an open milieu that is susceptible to change; and 3) universities can support health promotion initiatives through appropriate infrastructures. University students are an important part of the young adult population, which is the largest segment of young societies such as the KSA's. Based on these criteria, we selected university students with the aim of exploring different physical activity parameters, including self-efficacy, as well as perceived barriers and benefits for physical activity in Saudi women.

\section{Materials and methods Population}

The study participants were first-year university students at Princess Nora Bint Abdul Rahman University (PNU), Faculty of Rehabilitation and Health Sciences, Riyadh, KSA, recruited for the study in 2014. PNU is a female-only university in the KSA that aims to educate Saudi women. The study population was taken from seven bachelor's programs in health and well-being: health education and promotion, epidemiology, physiotherapy, occupational therapy, audio and speech, clinical nutrition, and radiology. The current study is cross-sectional and involved 94 female students who were 18-22 years old. Ethical approval was obtained from the College Council of Research at PNU. Each subject gave written informed consent to participate in this study.

\section{Questionnaire}

The questionnaire was self-administered and had five parts: 1) questions related to anthropometric and sociodemographic characteristics; 2) the Arab Teens Lifestyle (ATLS) questionnaire; ${ }^{19}$ 3) the Barriers Self-Efficacy Scale (BARSE); 4) questions related to sex, social factors, and self-image; and 5) the Exercise Benefits/Barriers Scale (EBBS).

The first part involved standard questions on sex, weight, height, parents' educational levels, and professions, number of housekeepers, number of family members, and illnesses among close family members. The second part was the ATLS questionnaire, a questionnaire that was developed for Arabic youth and young adults. ${ }^{19}$ It was chosen as the most suitable scale for obtaining detailed information on the physical activity types, intensities, frequencies, and durations for this sample of young Saudi females. The ATLS has been used in studies on physical activity in the $\mathrm{KSA}^{8-12}$ and in other countries in the Arab world ${ }^{20-22}$ among adolescents and young adults. Physical activities on the questionnaire were assigned metabolic equivalent (MET) values. In addition, the ATLS includes ten questions on dietary habits and four questions on behaviors related to physical activity (where, with whom, when, and why the physical activities were performed).

The BARSE scale is used to assess self-efficacy, health beliefs, and motivation, which have all been shown to be related to sustained health behavior, including physical activity. ${ }^{23,24}$ The scale is built on the likelihood of a person's perceived ability to engage in physical activity three times/ week in the next 3 months in the face of barriers. The BARSE is based on 13 questions with a ranking of $0-100$ (at intervals of 10) ranging from not at all confident to highly confident; the higher the mean scale score (closer to 100), the higher the 
person's self-efficacy. The fourth part was developed based on literature and information from focus group discussions organized as part of the present study (conducted prior to the present study), and refers to social and cultural factors. More precisely, the fourth part considered five main social milieus (university, family, the Islamic community, girlfriends, and social networks) with regard to their hindering or encouraging physical activity; these questions have a ranking of -3 to +3 , ranging from hindering to encouraging. In addition, a number of questions related to media, self-image, and sex were added, using 5-point Likert scales for each item. Finally, the EBBS is a scale that has been previously used to identify perceived barriers to and facilitators of physical activity. ${ }^{25}$ The instrument is built on 43 questions divided into two dimensions, barriers and benefits. A 4-point Likert scale was used. The range for the overall score is $43-172$ (the higher the number, the more positively physical activity is perceived); for the benefits, the score is 29-116, and for the barriers, it is 14-56 (the higher the score, the more negatively physical activity is perceived).

A pilot test was performed with 30 students. Some minor changes were needed for the ATLS for it to fit the needs of this specific population. The qualitative data were generated in a subgroup of students from four focus group discussions of five to eight students each. The focus group discussion sessions showed that students are very inclined to dance, and thus dancing was added to the questionnaire in the category of moderate-intensity physical activity; these changes were approved by the original author of the ATLS. No other parts of the questionnaire were modified.

Cronbach's alpha was used to calculate the reliability of the BARSE and EBBS scales. The internal consistency (alpha) for the BARSE scale was 0.79 , and it was 0.83 for the EBBS scale, indicating good consistency for group comparisons.

\section{Statistical analyses}

Statistical analyses were performed using the SAS software package version 9.3 (SAS Institute, Cary, NC, USA). Descriptive statistics (means and frequencies) were calculated to describe the sociodemographic characteristics as well as individual ATLS items, sociocultural items, and the BARSE and EBBS scales. For the ATLS questionnaire, variables were created for the total minutes for individual activities and for moderate, high, and total physical activity. Similarly, variables based on MET were created. The ATLS allows for calculating all the above, because it gives information on times/week and minutes/day for all individual activities. MET calculations are based on total physical activity. ${ }^{26}$ Activities are also grouped as "moderate" or "high" based on the METs for each of the activities. Based on WHO recommendations, ${ }^{27}$ a minimum of 150 minutes/week of moderate-intensity physical activity is required for adults (equivalent to 600 MET minutes/week). Physical activity was used as a continuous variable and was also based on the cutoff of 600 MET minutes/week of moderate physical activity. For the latter, the threshold for each individual was based solely on moderate physical activity levels (MET minutes from high physical activity were not included). Sedentary behavior was defined based on two questions (time spent watching TV and/or DVDs/videos per day and time spent on the computer and/or the Internet). The combined time for being sedentary was truncated at 16 hours/day to ensure a reasonable and realistic level of physical activity (as advised by the ATLS guidelines). Body mass index (BMI) was calculated as follows: weight $\left(\mathrm{kg} /\right.$ height $\left.\mathrm{m}^{2}\right)$. For dietary habits, a cut-off of $>3$ times/week was set for unhealthy food and of $<7$ times/week for healthy food.

Individuals who had one or more missing values for a specific activity were completely excluded in the calculations of total minutes for moderate, high, and total physical activity, and for MET minutes of moderate, high, and total physical activity. For the BARSE and the EBBS, if more than $5 \%$ of the items were unanswered, the individuals were considered missing and were excluded (more than one item for the BARSE and more than two items for the EBBS). Otherwise, the missing values for specific items were replaced by the mean values calculated from the remaining items.

Pearson's correlation coefficients were calculated to evaluate the association between physical activity and BMI with various variables. The Student's $t$-test was used to test the differences between the active and inactive students (based on the cut-off value of 600 points for MET) for the BARSE and EBBS scales. The BARSE scale, EBBS overall scale, EBBS benefits subscale, and EBBS barriers subscale scores were normally distributed (graphic representation, skewness, and kurtosis features), and therefore were fit for the Student's $t$-test. Statistical significance was taken at $P<0.05$.

\section{Results}

Table 1 presents the participants' sociodemographic characteristics and eating habits. The average BMI was $22.4 \pm 4.4 \mathrm{~kg} / \mathrm{m}^{2}$, and the average age was $20.0 \pm 0.7$ years. Both fathers and mothers of the students had relatively high educational levels (53.2\% and $40.3 \%$, respectively), but only a small percentage of the mothers $(23.4 \%)$ worked 
Table I Sociodemographics and eating habits of female Saudi university students

\begin{tabular}{ll}
\hline Sociodemographics $(\mathbf{n}=\mathbf{7 7})$ & Mean \pm SD or $\mathbf{n}(\%)$ \\
\hline BMI $\left(\mathrm{kg} / \mathrm{m}^{2}\right)$ & $22.4 \pm 4.4$ \\
Age $(\mathbf{y})$ & $20.0 \pm 0.7$ \\
Father's education & \\
$\quad$ High & $4 \mathrm{I}(53.2 \%)$ \\
Mother's education & $31(40.3 \%)$ \\
$\quad$ High & \\
Father working outside & $61(79.2 \%)$ \\
Yes & \\
Mother working outside & $18(23.4 \%)$ \\
Yes & \\
Housekeeping & $52(67.5 \%)$ \\
Yes & $26(33.8 \%)$ \\
Members of family ill in the last year & \\
Yes & $28(36.4 \%)$ \\
Eating habits & $17(22.1 \%)$ \\
Daily breakfast & $4(5.2 \%)$ \\
Daily vegetables & $26(33.8 \%)$ \\
Daily fruit & $32(41.6 \%)$ \\
Daily dairy & $32(41.6 \%)$ \\
Soft drinks $>3$ times/week & $36(46.8 \%)$ \\
Fast food $>3$ times/week & $35(45.5 \%)$ \\
French fries $>3$ times/week & $50(64.9 \%)$ \\
Cakes $>3$ times/week & $3(3.9 \%)$ \\
Sweets $>3$ times/week &
\end{tabular}

Abbreviations: BMI, body mass index; SD, standard deviation; $y$, years.

outside of the home compared with the fathers (79.2\%). Approximately $68 \%$ of the students' families had at least one housekeeper. One-third of the participants had at least one ill family member within the previous year because of chronic diseases such as diabetes, cancer, heart disease, etc. Regarding daily dietary habits, $36.4 \%$ of the participants had breakfast, $22.1 \%$ had vegetables, $5.2 \%$ had fruit, and $33.8 \%$ had dairy. With regard to "unhealthy dietary habits," fast food (including international and local fast food chains) and soft drink consumption of more than three times/week were both at $41.6 \%$, and French fry consumption more than three times/week was $46.8 \%$. A high consumption of cakes (including biscuits, donuts, etc) and sweets was also observed (45.5\% and 64.9\%, respectively). Energy drink consumption was very low $(3.9 \%)$.

Table 2 shows the levels of physical activity for individual activities and for activities categorized as moderate or high in total minutes and MET minutes. Walking, household work, and moderate intensity sports (dancing was often chosen) were the most preferred activities, with $101 \pm 114,90 \pm 150$, and $68 \pm 175$ minutes/week, respectively. Overall, students reported more time spent in moderate than in high physical activity during the week ( $267 \pm 269$ vs $47 \pm 53$ minutes/week). Among high-intensity physical activities, running/jogging
Table 2 Physical activity levels for individual activities, for the categories of "moderate", "high", and "total” in terms of min/week and MET min/week for female Saudi university students

\begin{tabular}{|c|c|}
\hline Individual physical activity $(\mathrm{n}=68)$ & Mean \pm SD \\
\hline Walk (min/week) & $101 \pm 114$ \\
\hline Stairs (min/week) & $13 \pm 12$ \\
\hline Run/jog (min/week) & $16 \pm 26$ \\
\hline Cycle (min/week) & $6 \pm 24$ \\
\hline Swim (min/week) & $14 \pm 40$ \\
\hline Moderate intensity sports (min/week) & $68 \pm 175$ \\
\hline Self-defense (min/week) & $0 \pm 1.8$ \\
\hline Weight training/body building (min/week) & $12 \pm 25$ \\
\hline Household work (min/week) & $90 \pm 150$ \\
\hline \multicolumn{2}{|l|}{ Individual physical activity ( $\left.{ }^{\mathrm{M} E T}\right)(\mathrm{n}=68)$} \\
\hline Walk (MET min/week) & $37 I \pm 438$ \\
\hline Stairs (MET min/week) & $102 \pm 94$ \\
\hline Run/jog (MET min/week) & $127 \pm 208$ \\
\hline Cycle (MET min/week) & $48 \pm 195$ \\
\hline Swim (MET min/week) & $56 \pm 160$ \\
\hline Moderate intensity sports (MET min/week) & $273 \pm 70$ I \\
\hline Self-defense (MET min/week) & $2 \pm 15$ \\
\hline Weight training/body building (MET $\mathrm{min} /$ week) & $94 \pm 202$ \\
\hline Household work (MET min/week) & $269 \pm 449$ \\
\hline \multicolumn{2}{|l|}{ Total minutes of physical activity $(n=68)$} \\
\hline Moderate $(\mathrm{min} /$ week) & $267 \pm 269$ \\
\hline High (min/week) & $47 \pm 53$ \\
\hline Total (min/week) & $317 \pm 289$ \\
\hline \multicolumn{2}{|l|}{ Total MET minutes of physical activity $(n=68)$} \\
\hline Moderate (MET min/week) & $957 \pm 1,005$ \\
\hline High (MET min/week) & $372 \pm 422$ \\
\hline Total (MET min/week) & $1,339 \pm 1,213$ \\
\hline 'bedentariness (h/day) & $6.2 \pm 3.5$ \\
\hline
\end{tabular}

Notes: a Metabolic Equivalent Task value; ' 90 observations available for this variable. Abbreviations: h, hours; MET, Metabolic Equivalent Task; min, minutes; n, number of students; SD, standard deviation.

was the only activity on which a relatively high percentage of the students spent some time during the week (approximately $53 \%$ of students spent $>0$ minutes/week). Fifty-six percent of the participants were categorized as physically "active" based on the cut-off of 600 MET minutes/week of moderate physical activity. Regarding sedentary levels, an average of $6.2 \pm 3.5$ hours/day sitting still was observed.

When physical activity was studied as a continuous variable (total minutes of physical activity/week), it was not associated with BMI or with being sedentary $(\mathrm{r}=-0.08$, $P=0.52$; and $\mathrm{r}=-0.15, P=0.23$, respectively). Being sedentary was positively significantly associated with BMI ( $\mathrm{r}=0.35$, $P=0.0014$ ), and moderate physical activity was positively significantly associated with high physical activity $(\mathrm{r}=0.34$, $P=0.0041$ ).

Table 3 describes behaviors related to physical activity as part of the ATLS questionnaire, as percentages. For each question, more than one option was available, and therefore 
Table 3 Behaviors related to physical activity from Arab Teens Lifestyle questions for female Saudi university students

\begin{tabular}{ll}
\hline Places for physical activity (n=78) & Yes \\
\hline Home & $72(92.3 \%)$ \\
School & $13(16.7 \%)$ \\
Park/public & $15(19.2 \%)$ \\
Sports & $2(2.6 \%)$ \\
Club & $7(9.0 \%)$ \\
Other & $3(3.8 \%)$ \\
With whom & \\
Alone & $62(79.5 \%)$ \\
Friends & $19(24.4 \%)$ \\
School peers & $5(6.4 \%)$ \\
Parents & $11(14.1 \%)$ \\
Other relatives & $8(10.3 \%)$ \\
Other & $12(15.4 \%)$ \\
When & \\
Morning & $32(41.0 \%)$ \\
Noon & $3(3.8 \%)$ \\
Afternoon & $13(16.7 \%)$ \\
Evening & $25(32.0 \%)$ \\
After evening meal & $10(12.8 \%)$ \\
No specific time & $31(39.7 \%)$ \\
Reasons for physical activity & \\
Health & $56(71.8 \%)$ \\
To lose weight & $39(50.0 \%)$ \\
Social & $4(5.1 \%)$ \\
Recreation & $10(12.8 \%)$ \\
Competiton & $5(6.4 \%)$ \\
Others & $10(12.8 \%)$ \\
\hline
\end{tabular}

Abbreviation: $n$, number of students.

the frequencies are not complementary. The data show that students exercise at home (92.3\%) and alone (79.5\%), and that their main reasons were for health $(71.8 \%)$ or for losing weight $(50.0 \%)$. The students exercised mostly during the morning $(41.0 \%)$ or the evening $(32.0 \%)$.

Table 4 BARSE scale individual items for female Saudi university students

\begin{tabular}{ll}
\hline BARSE items $(\mathbf{n}=\mathbf{8 9})$ & Mean \pm SD \\
\hline Bad weather & $36 \pm 23$ \\
Bored by program/activity & $37 \pm 21$ \\
Vacation & $61 \pm 29$ \\
Not interested in the activity & $36 \pm 23$ \\
Pain when exercising & $38 \pm 27$ \\
Exercise alone & $59 \pm 31$ \\
Not fun or enjoyable & $39 \pm 26$ \\
Difficult to get to exercise location & $44 \pm 27$ \\
Did not like the activity involved in & $34 \pm 22$ \\
Schedule problems & $35 \pm 27$ \\
Self-conscious about appearance & $46 \pm 31$ \\
No encouragement from instructor & $44 \pm 29$ \\
Under personal stress & $39 \pm 26$ \\
BARSE average & $42 \pm 14$
\end{tabular}

Abbreviations: BARSE, Barriers Self-Efficacy Scale; $n$, number of students; SD, standard deviation.
Table 4 displays the means for the 13 individual items on the BARSE scale as well as for the overall scale. The highest point scores appeared for vacation $(61 \pm 29)$ and exercise alone (59 \pm 31$)$; being self-conscious about one's appearance had a high score as well $(46 \pm 31)$. The overall point scores showed low self-efficacy, with the average total score being $<50$ $(42 \pm 14)$. All other factors had an average score of $<50$, showing low self-efficacy.

When the students were categorized as active or inactive (based on the 600 MET minutes/week cut-off), the Student's $t$-test showed significant differences for the overall BARSE scores ( $46 \pm 13$ vs $37 \pm 15, P=0.02$ ). Information relating to social factors showed that among different social settings (university, family, the Islamic community, girlfriends, online), the university was the only setting that hindered physical activity; the results showed that $32 \%$ of the students selected the university, compared with 19\% for family, $15 \%$ for the Islamic community, $7 \%$ for girlfriends, and 13\% for online networks and social media.

Table 5 shows the students' responses as frequencies for the categories agree, neutral, and disagree on questions related to self-image, attitudes toward physical activity, and physical activity and sex. Forty-four percent of the students disagreed that they would change their diets rather than engage in physical activity if they wanted to lose weight. Sixty percent of the students agreed that a healthy body shape has curves, but $98 \%$ of them agreed that it is important for a woman to have a fit and healthy body. With regard to sex, $66 \%$ agreed that it is easier for men to be physically active than for women, and $60 \%$ agreed that men are more physically active than women.

Regarding the EBBS, the overall scale mean score was $131 \pm 10$; for the benefits and barriers subscales, the point scores were $95 \pm 10$ and $34 \pm 5$, respectively, showing that physical activity is positively perceived by the students. With the individual items for benefits, the students agreed or strongly agreed on most of them, thus showing awareness of the effects of physical activity for health and well-being. The students had high percentages of disagreement for the following: 1) exercising lets me have contact with friends and persons I enjoy (41\%); 2) exercising is a good way for me to meet new people (33\%); and 3) exercising increases my acceptance by others (33\%). Regarding barriers, there were shared responses for most items. The students considered one important barrier to be that locations for exercise were too far away ( $52 \%$ agreed) and that there were too few places to exercise (75\% agreed). They mostly disagreed that family members ( $66 \%$ disagreed) or feeling embarrassed to exercise were barriers to physical activity (71\% disagreed). No association was found when students were categorized as 
Table 5 Physical activity and sex, attitudes, and self-image for female Saudi university students

\begin{tabular}{|c|c|c|c|}
\hline Students, $\mathrm{n}=90$ & Agree & Neutral & Disagree \\
\hline $\begin{array}{l}\text { If I want to lose weight, I would change my diet rather than } \\
\text { engage in physical activity }\end{array}$ & $30(33 \%)$ & $21(23 \%)$ & $39(44 \%)$ \\
\hline In my mind, a healthy body shape has curves & $54(60 \%)$ & $25(28 \%)$ & II (I2\%) \\
\hline It is important that a woman has a fit and healthy body shape & $88(98 \%)$ & $2(2 \%)$ & $0(0 \%)$ \\
\hline It is easier for men than women to be physically active & $60(66 \%)$ & $16(18 \%)$ & $14(16 \%)$ \\
\hline Men are more physically active than women & $53(60 \%)$ & $15(17 \%)$ & $21(23 \%)$ \\
\hline
\end{tabular}

active vs inactive for the overall scale (132 \pm 11 vs $130 \pm 10$, $P=0.44)$, for the benefits scale ( $95 \pm 9$ vs $95 \pm 10, P=0.93$ ) or for the barriers scale ( $33 \pm 5$ vs $34 \pm 5, P=0.21)$.

\section{Discussion}

To our knowledge, this is the first study to consider in depth a number of sociocultural factors related to physical activity among Saudi females. In the current study, among first-year university students, we found that female Saudi students had low levels of physical activity and high levels of sedentariness. There was an observed overall low self-efficacy that was associated with physical activity. In addition, the young women perceived physical activity as beneficial, but their physical activity levels were low. The students showed awareness of the health-related and well-being benefits of physical activity, and they considered the lack of physical activity facilities a more important barrier than their families or society.

The main focus of the present study was not physical activity levels but physical activity-related sociocultural factors. However, our results are in agreement with those of previous studies with regard to the low levels of physical activity (and also with moderate physical activity levels being more common than high levels), ${ }^{8,10,14}$ the high sedentariness levels, , ,8,10,14 and dietary habits (high percentages of unhealthy food consumption). ${ }^{8}$ For specific activities, our study showed a preference for walking, household activities, and moderateintensity sports, including dance. Another study also showed a preference for household activities and walking but not moderate-intensity physical activity such as dancing, very likely because dance is a modification that we added to the ATLS in our study. ${ }^{10}$ In a previous study, jogging and swimming were also reported as preferred activities. ${ }^{14}$ Finally, in our study, moderate-intensity physical activity was positively associated with high-intensity physical activity, suggesting that students who are more active tend to be active at both moderate and high levels.

Students reported that they exercised mostly alone, and that factor did not appear to decrease their self-efficacy.
In the same line of evidence, meeting new people or getting together with friends was not a benefit related to physical activity. In addition, the students exercised at home, and in another study, Saudi adolescents also reported that they exercised alone and at home. ${ }^{11}$ If this is a genuine preference, then assumed barriers for physical activity for Saudi women related to isolation and restrictions on going outside do not appear to be a major concern. However, these results should be interpreted with caution, because they might also reflect the lack of choice and/or habits rather than preferences.

Interestingly, our results demonstrated that the students chose physical activities for their health and for losing weight. The results from the EBBS scale also showed that the students are aware of the benefits of physical activity, for their health and their well-being. In addition, the students appear to consider physical activity to be as important as diet for losing weight and think that having a healthy body is crucial. Highly scored perceived benefits of physical activity were observed in another study on Saudi students (the only other study that used a benefits/barriers scale, to our knowledge). ${ }^{17}$ It must be noted that in our sample, the parents had relatively high educational backgrounds, which could be significant in encouraging overall health knowledge. Young Saudis from different socioeconomic backgrounds might have lower levels of awareness of physical activity. ${ }^{7}$ In addition, our students are part of health science programs and therefore might be more sensitive to and knowledgeable about health (even though they are first-year students).

With regard to sociocultural barriers, information from our questions about different social factors showed encouragement toward physical activity from families, the Islamic community, friends, and social media, but less from the university. Among the barriers to physical activity, family discouragement was one of the least considered. Another study, however, showed that norms and traditions can be significant barriers to physical activity in the KSA. ${ }^{18}$ It must be emphasized that in this study, older Saudi females and those from different socioeconomic backgrounds were also studied, which implies that at least some of them were 
conservative. Regarding the role of universities, it is important to mention that PNU is a newly established university that does not yet have available organized physical facilities. The schedule for students does not allow for any involvement in physical activity (students are picked up after study hours and do not spend additional time at PNU). Based on this, the students would benefit enormously from PNU physical activity facilities if these were to be developed and offered in a systematic way.

The students' being self-conscious about their appearance did not show low self-efficacy, and feeling embarrassed about exercising was also not a barrier to physical activity. Sixty percent of students agreed that a healthy body should have curves, and Arabic women appear to be comfortable with having curvy bodies, as has also been reported by others. $^{28}$

Interestingly, the greatest barrier for students was the lack of facilities and their distance, which also agrees with other studies. ${ }^{17,18,29}$ However, in two of these studies, ${ }^{17,18}$ both men and women were included, and limited facilities was a common barrier. That is, this appears to be a significant barrier for men as well; in our study, the students did not clearly disagree regarding whether it was easier for men to be active or that men were more active than women, suggesting that sex differences are not particularly significant.

Overall, students perceived physical activity positively, just as in other studies. ${ }^{17}$ However, the overall scores were not associated with physical activity when the students were categorized as active or inactive. This can likely be explained by the fact that positive opinions about physical activity and health in general are not necessarily accompanied by appropriate actions. In other words, a high level of awareness does not always lead to actions that promote a healthier lifestyle. Self-efficacy regarding performing physical activities in our study was overall relatively low, requiring further study. Selfefficacy was, however, significantly positively associated with physical activity, suggesting that students who were more motivated were more active as well. ${ }^{30}$

Some of the strengths and limitations of the current study need to be considered. A major strength is that this study is the first to provide a considerable amount of information on sociocultural factors related to physical activity among young Saudi women. An additional strength is the use of the ATLS, a validated questionnaire for Arab youth and therefore an excellent tool for assessing physical activity and factors related to physical activity in our population. The main limitation of this study is that it involved university students from the capital, who do not represent all students in the KSA or all women of different ages and socioeconomic backgrounds. In addition, the students had health-related study backgrounds, which likely led to their acknowledging the benefits of physical activity.

\section{Conclusion}

In conclusion, the lack of facilities and lack of encouragement from PNU appear to be the major barriers to greater physical activity in female students. However, there does appear to be sufficient knowledge about physical activity itself and also encouragement from families and social surroundings. In that context, developing more culturally sensitive exercise facilities for women, as well as creating more facilities and implementing university health promotion programs for physical activity would be of great value, at least for educated Saudi females.

\section{Acknowledgments}

We are grateful for the cooperation of the students who participated in the current study. We thank Eva Ladekjær Larsen for her involvement in developing the scientific protocol, as well as Noura Abd Almoither for her contribution in organizing certain administrative tasks regarding the study.

\section{Disclosure}

The authors report no conflicts of interest for this work.

\section{References}

1. World Health Organization. WHO STEPwise Approach to NCD Surveillance. Country-specific STANDARD REPORT. Saudi Arabia 2005.

2. Al-Hazzaa HM. Health-enhancing physical activity among Saudi adults using the International Physical Activity Questionnaire (IPAQ). Public Health Nutr. 2007;10(1):59-64.

3. Al-Nozha MM, Al-Hazzaa HM, Arafah MR, et al. Prevalence of physical activity and inactivity among Saudis aged $30-70$ years. A populationbased cross-sectional study. Saudi Med J. 2007;28(4):559-568.

4. Bauman A, Ainsworth BE, Sallis JF, et al. The descriptive epidemiology of sitting a 20-country comparison using the international physical activity questionnaire. Am J Prev Med. 2011;41(2):228-235.

5. Sisson SB, Katzmarzyk PT. International prevalence of physical activity in youth and adults. Obes Rev. 2008;9(6):606-614.

6. Mabry RM, Reeves MM, Eakin EG, Owen N. Evidence of physical activity participation among men and women in the countries of the Gulf Cooperation Council: a review. Obes Rev. 2010;11(6):457-464.

7. Taha AZ. Self-reported knowledge and pattern of physical activity among school students in Al-Khobar, Saudi Arabia. East Mediterr Health J. 2008;14(2):344-355.

8. Al-Hazzaa HM, Abahussain NA, Al-Sobayel HI, Qahwaji DM, Musaiger AO. Physical activity, sedentary behaviors and dietary habits among Saudi adolescents relative to age, gender and region. Int J Behav Nutr Phys Act. 2011;21(8):140-153.

9. Al-Hazzaa HM, Al-Sobayel HI, Abahussain NA, Qahwaji DM, Alahmadi MA. Association of dietary habits with levels of physical activity and screen time among adolescents living in Saudi Arabia. J Hum Nutr Diet. 2014;27(Suppl 2):204-213. 
10. Al-Nuaim AA, Al-Nakeeb Y, Lyons M, et al. The prevalence of physical activity and sedentary behaviours relative to obesity among adolescents from Al-Ahsa, Saudi Arabia: rural versus urban variations. J Nutr Metab. 2012;2012:417589.

11. Al-Hazzaa HM, Alahmadi MA, Al-Sobayel HI, Abahussain NA, Qahwaji DM, Musaiger AO. Patterns and determinants of physical activity among Saudi adolescents. J Phys Act Health. 2014;11(6):1202-1211.

12. Khalaf A, Ekblom Ö, Kowalski J, Berggren V, Westergren A, Al-Hazzaa H. Female university students' physical activity levels and associated factors-a cross-sectional study in southwestern Saudi Arabia. Int J Environ Res Public Health. 2013;10:3502-3517.

13. Al-Eisa ES, Al-Sobayel HI. Physical activity and health beliefs among Saudi women. J Nutr Metab. 2012;2012:642187.

14. Al-Nakeeb Y, Lyons M, Collins P, et al. Obesity, physical activity and sedentary behavior amongst British and Saudi youth: a cross-cultural study. Int J Environ Res Public Health. 2012;9(4):1490-1506.

15. Al-Hazzaa HM, Al-Nakeeb Y, Ducan MJ, et al. A cross-cultural comparison of health behaviors between Saudi and British adolescents living in urban areas: gender by country analyses. Int J Environ Res Public Health. 2013;10(12):6701-6720.

16. Rasheed P. Perception of body weight and self-reported eating and exercise behavior among obese and non-obese women in Saudi Arabia. Public Health. 1998;112(6):409-414.

17. Gawwad ES. Stages of change in physical activity, self efficacy and decisional balance among Saudi university students. J Family Community Med. 2008;15(3):107-115.

18. Amin TT, Suleman W, Ali A, Gamal A, Al Wehedy A. Pattern, prevalence and perceived personal barriers toward physical activity among adult Saudis in Al-Hassa, KSA. J Phys Act Health. 2011;8(6):775-784.

19. Al-Hazzaa HM, Mosaiger AO; ATLS Research Group. Arab Teens Lifestyle Study (ATLS): objectives, design, methodology and implications. Diabetes Metab Syndr Obes. 2011;4:417-426.
20. Musaiger AO, Al-Mufty BA, Al-Hazzaa HM. Eating habits, inactivity, and sedentary behavior among adolescents in Iraq: sex differences in the hidden risks of noncommunicable disease. Food Nutr Bull. 2014; 35(1):12-19.

21. Allafi A, Al-Haifi AR, Al-Fayez MA et al. Physical activity, sedentary behaviours and dietary habits among Kuwaiti adolescents: gender differences. Public Health Nutr. 2014;17(9):2045-2052.

22. Kilani H, Al-Hazzaa H, Waly MI, Musaiger A. Lifestyle habits: diet, physical activity and sleep duration among Omani adolescents. Sultan Qaboos Univ Med J. 2013;13(4):510-519.

23. Bandura A. Self-efficacy: towards a unifying theory of behavioral change. Psychol Rev. 1977;84(2):191-215.

24. McAuley E. The role of efficacy cognitions in the prediction of exercise behavior in middle-aged adults. J Behav Med. 1992;15(1):65-88.

25. Sechrist KR, Walker SN, Pender NJ. Development and psychometric evaluation of the exercise benefits/barriers scale. Res Nurs Health. 1987; 10(6):357-365.

26. Ridley K, Ainsworth BE, Olds TS. Development of a compendium of energy expenditures for youth. Int J Behav Nutr Phys Act. 2008;5:45.

27. World Health Organization (WHO). Global recommendation on physical activity for health. 2010. WHO, Switzerland.

28. Musaiger AO, bin Zaal AA, D'Souza R. Body weight perception among adolescents in Dubai, United Arab Emirates. Nutr Hosp. 2012;27(6):1966-1972.

29. Ali HI, Baynouna LM, Bernsen RM. Barriers and facilitators of weight management: perspectives of Arab women at risk for type 2 diabetes. Health Soc Care Community. 2010;18(2):219-228.

30. Hagger MS, Chatzisarantis N, Biddle SJ. The influence of self-efficacy and past behavior on the physical activity intentions of young people. J Sports Sci. 2001;19(9):711-725.
International Journal of Women's Health

\section{Publish your work in this journal}

The International Journal of Women's Health is an international, peerreviewed open-access journal publishing original research, reports, editorials, reviews and commentaries on all aspects of women's healthcare including gynecology, obstetrics, and breast cancer. The manuscript management system is completely online and includes

\section{Dovepress}

a very quick and fair peer-review system, which is all easy to use Visit http://www.dovepress.com/testimonials.php to read real quotes from published authors. 